Sheridan College

SOURCE: Sheridan Institutional Repository

Publications and Scholarship

Faculty of Humanities \& Social Sciences

(FHASS)

5-16-2012

\title{
Place, Ethics, and Everyday Eating: a Tale of Two Neighbourhoods
}

Josée Johnston

Alexandra Rodney

Michelle Szabo

Sheridan College, michelle.szabo@sheridancollege.ca

Follow this and additional works at: https://source.sheridancollege.ca/fhass_publications

Part of the Food Studies Commons, and the Sociology Commons

\section{SOURCE Citation}

Johnston, J., Rodney, A., \& Szabo, M. (2012). Place, Ethics, and Everyday Eating: a Tale of Two

Neighbourhoods. Sociology, 46(6), 1091-1108. doi:10.1177/0038038511435060

\section{(c) (i) $(\Theta$}

This work is licensed under a Creative Commons Attribution-Noncommercial-No Derivative Works 4.0 License. This Article is brought to you for free and open access by the Faculty of Humanities \& Social Sciences (FHASS) at SOURCE: Sheridan Institutional Repository. It has been accepted for inclusion in Publications and Scholarship by an authorized administrator of SOURCE: Sheridan Institutional Repository. For more information, please contact source@sheridancollege.ca. 
Place, Ethics, and Everyday Eating: A Tale of Two Neighbourhoods
46(6) $1091-1108$

(C) The Author(s) 2012

Reprints and permission: sagepub. co.uk/journalsPermissions.nav DOI: I0.I I77/00380385 I|435060 soc.sagepub.com

@SAGE

\title{
Josée Johnston
}

University of Toronto, Canada

\section{Alexandra Rodney}

University of Toronto, Canada

\section{Michelle Szabo}

York University, Canada

\begin{abstract}
In this article we investigate how 'ethical eating' varies across neighbourhoods and explore the classed nature of these patterns. While our focus is on 'ethical eating' (e.g. eating organics, local), we also discuss its relation to healthy eating. The analysis draws from interviews with families in two Toronto neighbourhoods - one upper and the other lower income. We argue that understandings and practices of 'ethical eating' are significantly shaped by social class as well as place-specific neighbourhood cultures which we conceptualize as part of a 'prototypical' neighbourhood eating style. People compare themselves to a neighbourhood prototype (positively and negatively), and this sets a standard for acceptable eating practices. This analysis helps shed light on how place is implicated in the maintenance and reproduction of class-stratified food practices.
\end{abstract}

\section{Keywords}

class, consumption, culture, ethical eating, food, neighbourhood, place

\section{Introduction: Ethical Eating, Class, and Place}

Sociologists, food scholars, and market researchers have devoted considerable attention to the social determinants of 'ethical eating'. The term 'ethical eating' is used in various ways, but, here, refers to food choices thought to ameliorate social and/or ecological injustices

\footnotetext{
Corresponding author:

Josée Johnston, Department of Sociology, University of Toronto, 725 Spadina Avenue, Toronto, Ontario, M5S 2J4, Canada.

Email: josee.johnston@utoronto.ca
} 
(e.g. fair trade, organics). Ethical eating ${ }^{1}$ is best thought of as a socially constructed, contested discourse containing myriad contradictions, rather than an objectively superior set of eating practices. Within ethical eating discourse, some issues are emphasized more than others (e.g. environment in North America) (Johnston, 2008; Johnston and Szabo, 2011) and privileged groups are generally better positioned to engage with this discourse (Johnston et al., forthcoming). Ethical eating discourse has an undeniable moral tone, as well as a connection to class privilege (Govindasamy et al., 1998; Lockie, 2009). Food preferences have long been associated with displays of cultural capital (Bourdieu, 1984), and ethical eating practices are no exception (Johnston and Baumann, 2010).

Ethical eating practices create and reproduce classed consumption habits, yet ethical consumption is not only about what people can afford to buy. Some high-income consumers don't engage with ethical eating, while certain low-income shoppers go to great lengths to do so (Johnston, 2008; Johnston and Szabo, 2011). To shed light on this complex situation, it is important to recognize that ethical eating is not simply an abstract or moral idea, but is concretized in physical and material relationships. As Bourdieu argues in his later work, cultural capital is located not only in social but in physical space $(1999,2005$; see also Lury, 1997; Savage, 2010; Skeggs, 2004). Ethical stores are often located in affluent neighbourhoods and may not feel accessible to those with fewer economic and cultural resources (Barnett et al., 2010; Johnston and Szabo, 2011). Further, ethical consumption may be a part of the food cultures of specific regions (Beagan et al., 2010).

While place and class clearly work together to shape ethical consumption, more research is needed to understand how this interaction plays out in everyday eating practices (Starr, 2009). To address this gap, we investigate how ethical eating varies across neighbourhoods with different retail environments and income levels. We focus on ethical eating, but also discuss its relationship to healthy eating - a necessary consideration given the tendency of some interviewees to conflate food ethics with health. Our analysis draws from 40 qualitative interviews with parents and their teenage children (ages 13-19) in two Toronto neighbourhoods: the upper-income neighbourhood of Riverdale, and the gentrifying neighbourhood of Parkdale.

We argue that understandings of ethical eating are significantly shaped by place-specific neighbourhood cultures that reflect and reproduce classed ways of eating. To conceptualize these cultures, we draw from the sociological study of culture and cognition, and develop the idea of a neighbourhood 'prototype'. The neighbourhood prototype reflects residents' perceptions of the typical eater in their neighbourhood, thereby incorporating people's perceptions of the material environment, as well as neighbourhood standards or ideals. By charting how people understand the prototypical neighbourhood eater, we shed light on the complex intersections between place, class and eating practices. People compare themselves - both positively and negatively - to a neighbourhood prototype that sets a standard for 'normal' eating practices.

Understanding the link between neighbourhood food culture and ethical eating directly relates to the reproduction of a stratified food system where marginalized populations lack the economic capital, cultural capital, and geographic mobility required to access high-status foods. If ethical eating constitutes a moral 'gold standard' for food consumption, then it is important to understand how access to this standard is facilitated by class and neighbourhood culture. Furthermore, because an individualistic, voluntary notion of 
ethical eating tends to dominate public discourse ${ }^{2}$ (e.g. Pollan, 2006), understanding the links between place, class and ethical eating can help challenge insinuations that lowerclass eaters are morally irresponsible.

Below, we review literature examining the intersection of place, health and ethical consumption. Next, we describe our interview sample and methods. Finally, we look at each site to better understand how the neighbourhood food environment and prototype relate to class and the eating practices described by participants.

\section{Place, Neighbourhood, and Ethical Eating}

Recent scholarship points to the importance of place in relation to ethical consumption. First, the presence of retailers selling ethical products in an area, and residents' awareness of these retailers, is related to ethical food purchases (Beagan et al., 2010; Brown et al., 2009; Popkin et al., 2005; Squires et al., 2001; Weatherell et al., 2003). The interrelation of store location and income also influences ethical eating. Ethical stores tend to be located in more affluent neighbourhoods, making access more difficult for non-residents or public transportation users (Baker et al., 2009; Ellaway and Macintyre, 2000; Govindasamy et al., 1998; Moore and Roux, 2006; Morland et al., 2002; Smith and Morton, 2009). For low-income individuals especially, barriers to engaging with ethical food opportunities include access, distance and cost (Baker et al., 2009; Beagan et al., 2010; Govindasamy et al., 1998; Smith and Morton, 2009). More broadly, scholars are recognizing that ethical consumption is intimately tied to 'systems of provision'; in other words, commodity chains, marketing and retail environments set broad parameters for what individual choices are possible (Seyfang and Paavola, 2008).

A second way ethical consumption relates to place is through geographically-based food and consumption cultures (DeSoucey, 2010; Oluwabamide and Akpan, 2010; Schultz, 2002; Storey et al., 2002). For example, consumers in census tracts where ethical consumption is already relatively common are more likely to engage in ethical practices (Starr, 2009). Starr (2009) in the USA and Beagan et al. (2010) in Canada found that some regions were more engaged in ethical consumption than others. In Beagan et al. (2010), participants on Canada's west coast felt that their ethical purchasing decisions contributed to the prevalence of ethical stores and markets in their area, suggesting that discourses and resources for ethical eating can be mutually reinforcing.

These place-specific consumer cultures have a significant class dimension (Bourdieu, 1999, 2005; see also Savage, 2010). If we understand class not as a static condition, but as something that is continually made through symbolic and material struggles (Skeggs, 2004; Wacquant, 1991), then both place and consumption appear implicated in this classmaking process. Place-based identifications often emerge as a 'shorthand way of speaking class' that makes overt references to class unnecessary (Skeggs, 2004: 15; see also Gidley and Rooke, 2010). While consumer spaces are theoretically open for all to enjoy, particular sites and regions (e.g. gentrified neighbourhoods, global cities) are distinguished by their classed consumption habits (Zukin, 2010). Butler and Robson (2003) use the term 'metropolitan habitus' to describe the distinct disposition and consumption habits of London's middle classes (see also Webber, 2007), and argue that neighbourhoods develop 'minihabituses' influenced by specific ideas of the neighbourhood (2003: 190-2). A 'geographical 
imaginary' can also work to 'fix' less privileged groups in marginalized locations; workingclass neighbourhoods are marked by a kind of 'pathological lack' that often carries associations of moral promiscuity (Gidley and Rooke, 2010: 97; Skeggs, 2004). Meanwhile, the middle classes enjoy the comfort that comes with participating in socially valorized consumption practices - like eating organic food (Guthman, 2008).

In sum, prior studies suggest that cities and neighbourhoods develop particular classed ways of consuming that both reflect and reproduce class identities. While culture and food scholars demonstrate how neighbourhoods and regions have place-specific, classed ways of consuming, what is less understood is exactly how these classed consumption habits are maintained and reproduced. How do neighbourhood residents influence each other, how are their consumption practices shaped by their retail environment, and how do they understand their neighbourhood as imposing certain consumption standards? In this article, we build on the aforementioned literature to address these questions. More specifically, we investigate how the intersection of place, class and material resources shapes perceptions of a typical neighbourhood diet and ethical eating.

To conceptualize the perceptions and habitual consumption decisions around food, we turn to cultural sociology, and Bourdieu's concept of the habitus - a concept that describes how a system of class-based dispositions are internalized, and subtly influence perceptions and actions (1984: 170). Bourdieu's work Distinction (1984) showed how privileged classes in 1970s France distinguished themselves through their 'good' taste in foods, and more recent work suggests a continued ability to display cultural capital through food choices, including ethical foods (Bennett et al., 2009; Johnston and Baumann, 2010; Mellor et al., 2010). The concept of habitus, and Bourdieu's work more generally, suggests that people unconsciously enact their objective social structure, and that access to cultural assets or resources are based on people's social position.

One critique of the habitus concept is its black box quality (e.g. Boudon, 1998). In other words, how do we know the processes by which the habitus is constructed? Recent research in social psychology gives empirical force to the idea of habitus, affirming that many decisions are rooted in intuitive, habitual ways of thinking and acting (Chaiken and Trope, 1999). Sociologists have drawn from social psychology, psychology and neuroscientific research to illuminate how subconscious rules of thought create possibilities for thinking and acting (Douglas, 1966; Fleck, 1979; Vaisey, 2008, 2009). This cultural and cognition research builds on past sociological insights - like Giddens' (1984) distinction between 'practical' or automatic consciousness (intuitive decisions made during daily routines), and 'discursive' or deliberate consciousness (formal articulations and rationalizations for action). ${ }^{3}$ Not only is automatic consciousness influential in what we think, feel and do, but most cognition appears to occur at this level (Vaisey, 2009: 1681). These insights help explain why people's food ideals do not always match with actual food habits (Caplan, 1997: 5-6), and suggest that sociologists need to better appreciate how culture shapes food preferences in ways that are habitual and automatic.

Building on the idea that the habitus is shaped by place (e.g. Butler with Robson, 2003), we argue that residents articulate a place-based habitus through their descriptions of a prototypical neighbourhood eater that includes both positive and negative attributes. Employing the concept of 'prototypes' (developed by psychologist Eleanor Rosch, 1978, but taken up by sociologists, e.g. Cerulo, 2010), we map out habitual ideas shaping everyday food practices. Prototypes are the best example of a particular 
category (e.g. a 'chair' is a prototypical piece of furniture), and function as a kind of mental shorthand that allows for processing complex information with minimal cognitive effort (Rosch and Lloyd, 1978: 37, 28). A prototype is akin to Weber's (1949) conception of an ideal-type, but relies on social-psychological understandings of how people think and make classifications. While a Weberian ideal-type is an analytical construct developed by researchers and rooted in attempts to evaluate social phenomena (see Weber, 1949; Bruun, 2001; Eliaeson, 2000), the prototype is a way of getting at what Bourdieu (1977) called the 'logic of practice': the habitual, semi-conscious thought processes people employ to recognize and make sense of the neighbourhood eating style. People's awareness of, and self-positioning with, reference to the neighbourhood's prototypical eating style can be understood as one way habitus operates at the level of automatic consciousness. More specific to the topic of food, place and ethical eating, the prototype concept helps us understand how people implicitly make connections between a neighbourhood, its typical diet, the resources available to residents, and their own food practices.

In response to interview questions and photo elicitation, our interviewees painted a picture of a prototypical neighbourhood eating style that was both ideational and material: it included normative statements about dietary ideals, but also referenced material constraints, physical infrastructure, and supports for different eating styles. ${ }^{4}$ The prototypical neighbourhood diet was not a distant or abstract idea, but served as a reference point used in combination with other reference points (e.g. the 'good' mother, parent, or family [James and Curtis, 2010; Lawler, 2000; Taylor, 2010]) to evaluate family food practices. In the section on analysis, we map out neighbourhood prototypes, and the mechanisms by which place of residence, community norms and resources interact to shape participants' involvement in ethical consumption.

\section{Data and Methods}

Our study draws on interviews with residents of two neighbourhoods in Toronto, a city with a population of 2.48 million. In each neighbourhood we interviewed at least one adult and one teen (ages 13-19) from 10 families, totaling 20 families and 47 participants. Parents and teens were interviewed separately in the family home. Each participant was interviewed twice resulting in 40 interviews. In addition to interviews, we asked participants to take approximately 20 photos of 'food in their life'. 5

The two neighbourhoods, South Parkdale and North Riverdale (hereafter 'Parkdale' and 'Riverdale'), are relatively close to each other geographically, but differ significantly. Riverdale is located just east of the downtown core. The population is somewhat diverse, but tends towards a middle, or upper middle class base that self-identifies as 'white' or 'Caucasian'. The most recent census data (Statistics Canada, 2010) indicate that Riverdale is relatively affluent and well educated. A substantial percentage of the population has a university education (46\%), as compared to the Toronto average of 27 per cent. The average household income, in 2006 dollars, was \$96,006 (City of Toronto, 2006). In terms of the retail strip, Riverdale has a number of trendy clothing and lifestyle stores, upscale cafes, specialty food shops and a green-living store. It is home to a large worker-owned food coop, The Big Carrot, that sells a range of organic, local and 'natural' groceries, and is housed in a plaza full of other similar retailers. 
Parkdale is a gentrifying neighbourhood that maintains a reputation for drugs and prostitution. Low-rent apartments coexist with large Victorian houses, many of which have been bought and renovated by upper middle class Torontonians (Slater, 2005). There is a good deal of income disparity, though the average Parkdale income is about 13 per cent below the city average (Slater, 2005). The population is ethnically and racially diverse. Approximately 56 per cent of residents are 'visible minorities', with Tibetan, Filipino, Black, Chinese and South Asian being the five most populous ethno-racial groups (Statistics Canada, 2006). The main Parkdale retail strip has greengrocers, a discount chain grocery store, fast food outlets, convenience stores and a handful of relatively new trendy restaurants. In comparison to Riverdale's main street, the Parkdale strip is somewhat stark, and displays greater class and ethno-racial diversity.

The participant families reflect the diversity of the two neighbourhoods. While there was not a perfect homology between status and neighbourhood, most Riverdale participants were 'white', and most had higher incomes, class designations, and education levels than Parkdale participants (see Table 1). ${ }^{6}$ In both neighbourhoods, mothers volunteered to be interviewed more readily than fathers, while the composition of male and female teenagers was roughly equal. This predominance of women produced gendered descriptions of family food practices, and while gender is not our primary focus in this article, we recognize the importance of gender and class intersectionality in these food practices. ${ }^{7}$ We began the data analysis process by coding interview transcripts using the qualitative data management software AtlasTi. Interviews were first coded for themes related to how local food cultures, socioeconomic status, and the family context interact to shape family food habits, including ethical eating. Additional codes were added as new themes emerged. We recorded participants' and families' overall approach to ethical eating (i.e. experiences of and thoughts about ethical eating) and how this related to other participants and families. We noted salient differences between the approaches and experiences of Riverdale and Parkdale families to ethical eating, and their conceptualizations of a 'prototypical' neighbourhood eating style.

\section{Analysis: Neighbourhood Food Environments and Prototypical Eating Styles}

This section maps out a prototypical eating style in each neighbourhood, and examines what part ethical eating plays in this prototype. First, we examine how the physical environment shaped possibilities for ethical consumption in each neighbourhood. While the analysis is influenced by our neighbourhood observations, it is primarily informed by participant depictions through interviews and photographs. Second, we analyse how participants constructed and related to the prototypical eater in their neighbourhood.

\section{Perceptions of Neighbourhood Food Environments}

The Riverdale Food Environment: 'Healthy-ethical' Choices Abound. Riverdale is a predominantly upper middle class neighbourhood, and familiarity with ethical eating discourse was very common in our interviews, even amongst participants with lower incomes. ${ }^{8}$ References to healthy and ethical eating went hand in hand, which is not surprising given that 'health food' stores are often places to find ethical products, and some products (e.g. organics) are understood to have health and eco-social benefits. The term 'organic' was 
Table I. Demographic summary

\begin{tabular}{lllc}
\hline Family characteristics & Parkdale & Riverdale & Total families \\
\hline Income & 2 & 5 & 7 \\
High & 1 & 1 & 2 \\
Middle & 7 & 4 & $1 \mathrm{I}$ \\
Low & & & \\
Education & 3 & 8 & 1 I \\
University degree or more & 5 & 1 & 6 \\
Some post-secondary & 2 & 1 & 3 \\
High school or less & & & 14 \\
Race/Ethnicity & 5 & 9 & 6 \\
White (Anglo-Saxon, European) & 5 & 1 & 7 \\
Non-white, mixed heritage & & & 8 \\
Class & 2 & 5 & 5 \\
Upper-middle & 5 & 3 & $\mathrm{n} / \mathrm{a}^{\mathrm{c}}$ \\
Lower-middle & 3 & 2 & $\mathrm{n} / \mathrm{a}$ \\
Working class/working poor/underclass & & & \\
Gender & $9 / 2$ & $9 / 4$ & \\
Parents (F/M) & $5 / 7$ & & \\
Teenagers (F/M) & & & \\
\hline
\end{tabular}

Notes:

aBased on the family member with the highest education level.

bFamilies were assigned to class categories based on occupation, since this characteristic usefully combines education, income and occupational prestige (Gilbert, 2008; Goldthorpe, 1987; Lamont, 1992). When couples differed, the class of the partner with the higher class was used. When immigrant families were underemployed, we placed them in the class category corresponding to their occupation of training. Upper middle class participants generally held professional or managerial jobs. Lower middle class participants included lower-level managers and administrators, lower-status white collar and some highly skilled blue collar workers. Working class/working poor/underclass participants had low-skill manual and clerical jobs, unstable work situations, or were supported by public assistance.

cMore than one parent or teen were interviewed in some families.

often conflated with ethical, and the ubiquity of organic produce in the retail environment promoted a sense that the neighbourhood offered a variety of health-promoting, ethical food choices.

A key element of the Riverdale food environment emphasized by participants was the tremendous diversity of food choices, including ethical products. When asked what kind of store or restaurant Riverdale lacked, most participants could think of no obvious omissions, and they emphasized the neighbourhood's variety. Neighbourhood affluence, and the presence of young professionals interested in 'ethical/healthy' food, was thought to contribute to this panoply of upper middle class 'healthy-ethical' food options. Bojana (48, lower middle class, Serbian-Canadian) noted: 'The whole area of Riverdale is a very good community for farmers' markets, for example. There are enough people with money to buy these things.' Bojana's comments speak to the affluent customer base and increased market development in neighbourhoods such as Riverdale, leading to intensified consumption of ethical products (Squires et al., 2001).

Participants' photographs also demonstrated a perception of Riverdale as having an abundance of healthful, ethical food options enabling residents to engage in these practices. 
Photographs depicted ethical food establishments like The Big Carrot, as well as close-up shots of organic mushrooms, local apples and a juice bar. While there are some fast food outlets in Riverdale, these were almost completely absent from participant photos. Fast food was seen by most participants as a neighbourhood blight. Several participants explained how their children refused to eat fast food, and detailed how a fast food chicken franchise (Swiss Chalet) had been forced out of business. Patricia (47, lower middle class, Japanese-Canadian) noted that residents celebrated its closure and that 'there was almost a stigma in the neighbourhood that you didn't want to buy there'.

In keeping with earlier research on fast food and class (e.g. Bugge, 2011), Riverdale's abundance of healthful, ethical food options appeared to confer social status on the area and its residents. For example, Claude (52, upper middle class, French), described the Riverdale eating style as 'sophisticated because of these [multiple food] options'. His response suggests a conflation between the neighbourhood retail options and its residents' appreciation of 'diversity', a term with moral and social weight in cosmopolitan cities (Butler with Robson, 2003: 165). In sum, abundant retail options in Riverdale were seen as both enabling healthy-ethical shopping and enabled by the 'sophisticated' and 'diverse' tastes of its residents. Moreover, social pressures (e.g. the stigma against fast food) reproduced the upper middle class neighbourhood culture and retail landscape.

The Parkdale Food Environment: Less Choice, More Fast Food. In contrast to the glowing descriptions of retail variety in Riverdale, our interviews revealed little sense of a healthy, ethical foodscape in Parkdale. Residents mentioned some neighbourhood stores selling ethical products, including a butcher selling sustainably raised meats and a fair trade coffee shop. However, these stores were all located on the gentrified edges of the neighbourhood, while most interviewees lived in the core. Unsurprisingly, these stores were frequented mainly by the two upper middle class families in our sample who lived on the gentrified eastern edge of Parkdale, and had vehicle access to stores within and outside the neighbourhood. The other eight Parkdale families, who did not own cars and were conscious of public transit expenses, made do with stores and restaurants within the neighbourhood core.

Despite the ethno-cultural variety in stores that Parkdale residents found pleasant and convenient, neighbourhood retailers were often described as lacking. For participants with an interest in ethical food issues, central Parkdale, where lower-income participants lived, offered little in the way of ethical products, especially affordable ones. One example comes from Marianne (49, lower middle class, European/Middle Eastern), a single mother living on a limited income. She was interested in products like sustainably raised fish, but didn't know where to purchase them locally, other than at a health food store she found 'outrageously expensive'. She also noted the costliness of going outside the neighbourhood for ethical products: 'That's five dollars [return transit fare] added on to the price of a piece of salmon.' Wendy (60, working-poor/underclass, white), a single grandmother on social assistance, similarly noted that she wanted to buy local produce 'for environmental reasons', but had trouble finding it at her neighbourhood grocery store.

Although some interviewees expressed concerns about ethical eating, this was not the primary concern for most Parkdale participants. A few participants displayed signs of food insecurity, and even for those who were food secure, food quality and healthfulness were key concerns. Instead of conflating healthy food with ethical food, as Riverdale participants did, Parkdale residents frequently contrasted healthy food with fast food. Shamar (15, 
lower middle class family, Tibetan) said: 'The restaurants and food stores here aren't that healthy for you ... All there is is fast food everywhere.' Other teens echoed this description of the ubiquity of fast food, and this was also reflected in participant photos. While there were images of grocery stores and 'ethnic' restaurants (e.g. Caribbean, Thai), photos of Burger King, McDonald's and takeaway pizza shops were much more common. A few residents saw fast food options as convenient, but many, such as Sarama (15, workingpoor/underclass family, Eritrean-Canadian), saw drawbacks. She was critical of Parkdale's food environment, particularly since she had medical problems attributed to her diet, and identified fast food outlets around her school as a 'temptation'. She noted: 'We should have less fast foods in the area so it's less [easy] for us to go there.' Some participants also identified a dearth of stores with fresh, high quality items. For instance, Kim (49, lower middle class, white), noted that some stores near her home had 'old' and 'dusty' products, and wished there were more options for high quality, affordable foods.

While Riverdale participants associated the healthy-ethical retail environment with their own sophisticated food tastes and saw themselves as having power over their foodscape (as when residents drove out Swiss Chalet), there was little evidence that Parkdale residents saw their food environment as changeable. This is in keeping with previous research on the sense of 'given-ness' in lower class participants' narratives about their circumstances (Lareau, 2002: 769; Savage, 2010: 131). It also reflects the fact that Parkdale residents generally had fewer financial resources and thus diminished market influence. Parkdale narratives did, however, suggest how the limitations of participants' food environment might influence their self-definition and social status. For example, in reference to farmers' markets (which she did not patronize), Wendy said:

Sometimes I think they're charging much more because their stuff is unique, because it's freshly grown nearby, it's organic ... for the caché of all that ... [I wonder] if they couldn't charge a little more reasonable price for your everyday person.

The 'caché' of ethical food is evident to Wendy, but as 'your everyday person' she sees it as out of her reach.

Participants portrayed Parkdale as a neighbourhood that at best did not facilitate, and at worst provided barriers to, ethical and healthy eating. The neighbourhood core was characterized as dominated by fast food, and lacking high quality, or 'ethical' food options. While the neighbourhood's gentrified outer edges offered more options, they were primarily accessed by affluent, mobile residents, who also described travelling throughout the city to get specific food products. Further, there was little evidence that Parkdale participants - especially those with lower incomes - saw themselves as empowered to change their food environment. The food environments in both Riverdale and Parkdale reflect how place, social class and food culture are mutually reinforcing, and how participants embody these food environments and reflect them in daily food practices.

\section{Prototypical Eating Styles in Riverdale and Parkdale}

Drawing from descriptions of neighbourhood eating styles as well as participants' food habits, we examine how interviewees depicted a prototypical neighbourhood diet, and address the classed nature of food ideals. 
The Riverdale Prototype:An Idealized Ethics-Health Hybrid. When asked to describe the typical eating style in Riverdale, most participants depicted an idealized health-conscious, ethical consumer favouring organic foods. Participants with high and low incomes frequently named The Big Carrot as a store where a typical Riverdale resident shopped, and as a place to take visitors. Marina (47, upper middle class, white), a mother of three, characterized it as 'a real Riverdale place, a big beautiful store to get healthy, organic food', while Ted (52, lower middle class, white), suggested that The Big Carrot 'influences a lot of people in the neighbourhood'. Patricia (47, lower middle class, Japanese-Canadian), described residents' attention to food ethics:

If I had to sum up [Riverdale residents] it would probably be quite knowledgeable, savvy about food ... two benchmarks are the Carrot Common and Sun Valley [another health-ethics grocery store]. ... that ethical basis for food plus local. And another tenet of Riverdale as well is that we would look into alternative or complementary lifestyle and food choices, medicines. So we would have a general support system with that type of lifestyle.

Patricia's comments echo other residents' perceptions of the prototypical Riverdale eater as interested in health and food ethics. Her use of the term 'savvy', like Claude's use of 'sophisticated' earlier, also emphasizes the status given these food habits.

While the Riverdale prototype serves as an idealized standard, it was also construed as difficult to emulate due to money and time constraints. Even though The Big Carrot was depicted as the prototypical Riverdale store, none of the Riverdale participants regularly shopped there because of perceived cost barriers (despite the relatively high incomes of some participants - see Table 1). Bojana (48, lower middle class, Serbian-Canadian) declared: 'I would like to be able to buy things non-stop from Big Carrot where I know it's good quality, it's organic, locally supplied. But my financial situation is not so good so I have to compromise these things.'

When the prototypical Riverdale diet could not be attained, some participants described feelings of guilt and anxiety. For example, in reference to the 'local' dimension of the ethical eating discourse, several expressed remorse for not using their backyard space to grow food, as in Patricia's case: 'I feel badly [about not growing food] . . I feel that I am almost being indulgent or wasteful about the space that I have.' Negative emotions were also articulated when the prototypical eating style was perceived as status-driven, especially when it came to children's consumption. As Krista (43, upper middle class, white) put it:

I think there's a bit of one-upmanship that goes on. Especially when you have kids in school ... the one-upmanship also going on in the schoolyard, that you don't send your kids with prepackaged lunches ... And the kids do it too, 'Oh I hate McDonald's'.

While some residents did occasionally eat fast food, fast food chains were frequently referenced as a foil to the prototypical Riverdale diet. Residents evoked the image of McDonald's as representative of 'low-quality', 'unhealthy', and 'socially irresponsible' food, thus defining what does not fit within the neighbourhood prototype. For example, Krista said that McDonald's serves 'lowest common denominator foods, and proudly spoke about how her kids wouldn't eat there even if she offered to take them. 
This reprobation of fast foods, often associated with the lower classes (Bugge, 2011; Warde, 1999), is in keeping with a long history in western culture of stigmatizing lowerclass bodies and the perceived excesses of their consumption habits (Gidley and Rooke, 2010: 99, 103). There is an equally long history of women being held responsible for the 'good' or 'bad' food habits of their families (James and Curtis, 2010). It is no wonder, then, that many Riverdale participants who did not follow the prototypical diet, especially mothers, felt guilty and ashamed. Marina, for instance, was self-conscious about not buying organic: 'We're not into [organics]. Most of my friends do eat organic food ... A lot of people in Riverdale eat organic.' Neither Marina or her husband trusted organic certification and she noted that she 'could give a crap about the environment', yet she still felt pressure to justify her choice. She mentioned several times that they 'couldn't afford' organics, even though the family has a high income. While Marina's sense of not living up to neighbourhood standards did not cause her to change her buying practices, the neighbourhood prototype directly influenced the habits of many other participants, both men and women. When participants could not meet neighbourhood standards, they described strategies for approximating them - by buying local, in-season foods rather than certified organics, or purchasing non-certified products from trusted sources.

Our interviews reveal that the prototypical Riverdale eating style revolves around health and food ethics, two concerns that carry significant social status and moral weight (Bugge, 2011; James and Curtis, 2010; Mellor et al., 2010) and are most easily acted on by residents with high incomes. They also reveal the socio-emotional mechanisms (e.g. guilt, shame) through which this prototype is reproduced.

The Parkdale Prototype: Fast Food, Food Insecurity, and Multicultural Diets. The prototypical diet described by Parkdale residents was less idealized than the Riverdale prototype, was centrally concerned with fast food, and made little reference to a neighbourhood ethical eating standard. In fact, the lack of such as standard was critiqued by one lower-middleclass family committed to ethical eating. The son, Marcus (18, lower middle class, BarbadianMiddle Eastern), criticized Parkdale residents for what he perceived as their inattention to food politics. The mother, Marianne (49, lower middle class, European/Middle Eastern), spoke about wanting to teach others about ethical eating, such as her local greengrocer, whom she was encouraging 'to label things and get more local, get more direct from farmers'. That Marianne felt a need to educate her (most likely lower class) neighbours and local shopkeepers about food ethics again speaks to the power of food and bodies as markers of class and sophistication (Gidley and Rooke, 2010). But what we would like to emphasize here is what Marianne's experience tells us about the Parkdale prototype. Marianne saw a void of knowledge about, and commitment to, ethical eating in her physical and social environment. This is a clear contrast with Riverdale participants, who perceived an abundance of ethical eating information around them.

Attitudes towards fast food differed significantly across the two neighbourhoods. In Parkdale, fast food was associated with health problems, but was also seen, particularly by teenagers, as the source of peer pressure and social status. Sarama (15, working-poor/ underclass family, Eritrean-Canadian) was worried about her health and weight but ate fast food nonetheless because 'it's a teenager thing'. She explained: 'Everyone's eating out and you don't want to bring [food] from home 'cause everybody's watching you'. For 
Sarama and other teens, fast food signaled freedom from parents (the supposed source of homemade food) and from 'adult' health concerns. (In contrast, Riverdale participants described both adults and youth being negatively judged for liking fast food or 'junky' food.) For Parkdale adults, social pressure to eat fast food was less evident, but there were signs that the prototypical Parkdale diet centred to some degree around fast food. When we asked Marika (46, lower middle class, Ukrainian) her impressions of eating in Parkdale, she mentioned the ubiquity and popularity of fast food places: 'You can find probably eight or ten takeaway shops in this particular intersection, and people are shopping there all the time.' Unlike many Riverdale participants who told us about their own (rare) fast food purchases with embarrassment or qualification, Marika added matter-of-factly that her family frequented these places, even for family outings (a key moment for 'family displays' and other-judgment around food [James and Curtis, 2010]). Though fast food eating was not equally sanctioned by all Parkdale participants, it was seen as somewhat 'normal' in the neighbourhood.

The prototypical understanding of Parkdale diets is undoubtedly related to the area's reputation, even among its own residents, as a haven for drug addicts, the unemployed, the poor and the mentally ill. When asked about typical eating habits in Parkdale, Marika (46, lower middle class, Ukrainian) described the neighbourhood as a place where people 'are living on welfare and don't have much money to shop'. April (13, underclass, white), a teen living on social assistance with her grandmother, referenced 'junkies [drug addicts]' in Parkdale, who 'don't eat too much'. As Gidley and Rooke (2010: 97) point out, cultural associations between poor neighbourhoods and their residents are often so strong that residents may be stigmatized 'by virtue of merely residing there'. We suggest that a similar process of association is going on in terms of the Parkdale prototypical eater, with residents imagining somebody who not only eats fast food, but has trouble accessing enough food, period. With this prototypical eater as a reference point, ethical eating concerns appeared outside the purview of most of Parkdale participants, especially those with lower incomes.

In terms of how the prototypical eating style impacted Parkdale participants, we again see a contrast with Riverdale. While Riverdale participants felt shameful about falling short of emulating the health-ethical prototype, Parkdale participants seemed to feel either on par with, or, in the case of middle class residents, superior to, the neighbourhood prototype. For example, Kim (49, lower middle class, white) admitted to being 'so judgmental' when she saw fellow grocery shoppers checking out with 'cases of pop and five bags of chips'. We attribute this to the 'low bar' of the Parkdale prototype and the neighbourhood's overall reputation. Participants noted that fellow residents were 'going to the food bank' or 'living on welfare' and thus set a low standard of comparison in terms of a culturally acceptable (i.e. middle class) diet. But whether they felt on par with, or superior to, the Parkdale prototype, the result was similar in terms of ethical eating: the neighbourhood prototype provided little social pressure to engage with ethical eating practices.

While the prototypical eating style in Parkdale was dominated by negative qualities, there were some positive dimensions that are important to mention briefly. In particular, some participants spoke passionately about the vibrant, multicultural aspects of Parkdale eating styles. Azzezza (44, working-poor/underclass, Eritrean) described potlucks at the 
local community centre where her family was able to discover new foods and make friends of other ethno-cultural backgrounds. Marianne appreciated being able to find food from all over the world: 'This neighbourhood really prides itself on its multicultural [character].' Thus, the prototypical Parkdale eater was less idealized than the Riverdale prototype, but it was multidimensional: participants invoked images of a fast food diet that is minimally engaged with ethical eating discourses, but also referenced a cosmopolitan eating style with food choices from multiple culinary backgrounds.

\section{Discussion and Conclusion}

While engagement with ethical eating discourse clearly depends on individual taste proclivities, sociologists have charted the influence of social factors on tastes, including cultural and economic capital, the influence of particular food cultures, and most significant for this article, place, or neighbourhood. Our interpretive analysis emphasizes the richness of investigating the mutual influence of these factors through discussions of food ideals and practices. Place, in the form of a neighbourhood retail environment and culture, shapes expectations of food choices, including engagement with ethical eating discourse. At the same time, the material resources available to neighbourhood residents impact the expectations and standards of local food cultures, as well as the ability of residents to meet these standards.

Our research into neighbourhood food culture centres around the concept of 'prototype', a conceptual tool capturing the automatic associations gleaned from residents' verbal and photographic impressions of a typical neighbourhood diet. To be clear, the prototype does not reflect a uniform neighbourhood diet. Instead, it is best understood as a cluster of characteristics representing the 'best fit' for how diet in a particular place is understood and related to. In the wealthier neighbourhood of Riverdale, the prototypical neighbourhood diet reflected upper middle class economic and cultural resources, clustered around concepts of good health, ethical eating and prioritized local and organic foods. Although none of the residents interviewed felt they could fully achieve these standards, most aspired to them nonetheless, in part, we suggest, because of social pressures causing them to feel judged, guilty, or uncomfortable when failing to comply. While some residents spoke of the high cost of healthy, ethical eating in Riverdale, most perceived the neighbourhood favourably as offering multiple options for healthy, ethical food choices.

In the gentrifying neighbourhood of Parkdale, the dietary prototype was less aspirational, and reflected the material constraints of its low-income residents. Ethical food concerns were not central characteristics of the neighbourhood prototype, which was instead focused on fast food - as a temptation, as a readily accessible and affordable meal choice, and as a source of status for teenagers. Our analysis suggests that there is no single way of relating to a prototypical neighbourhood diet, and that this relationship depends on available economic and cultural resources. Upper middle class gentrifiers in Parkdale had similar ideas about Parkdale's 'low' culinary standards and ubiquitous fast food options, but used their resources to exceed neighbourhood standards and access ethical food options at the outer edge of the neighbourhood or in different parts of the city. For low-income Parkdale residents, minimal resources restricted their food practices spatially to the neighbourhood core, which was perceived as offering minimal choice. Even in a gentrifying neighbourhood like 
Parkdale, we observed a local food culture shaped by a legacy of poverty and urban problems - a legacy which made it difficult (logistically, culturally, materially) for lowincome residents to take advantage of newer food trends like farmers' markets.

This work demonstrates how sociological research can productively use interpretive approaches to study how place-specific food cultures intersect with social class, and to map the cognitive processes guiding food choices. Together, these two neighbourhood prototypes work to reproduce a larger social understanding of affluent eaters as 'ethical', and lowerincome residents as relatively 'unethical', fast food eaters. While ethical foods have become a way of displaying cultural sophistication and moral concern, we show that place and privilege are just as important as personal taste and ethics in shaping daily food choices.

\section{Acknowledgements}

The Canadian Institute for Health Research (CIHR) generously funded this research. The principal investigators on this grant are Brenda Beagan (Dalhousie), and Gwen Chapman (UBC). Other investigators include Elaine Powers, Helen Valiantos, and post-doctoral fellows Deborah McPhail and Sonya Sharma. We are grateful for all ideas and inspiration provided by these researchers, but accept all limitations as our own.

\section{Notes}

1 While we emphasize the contested nature of the term 'ethical eating', we refrain from using quotation marks from this point on in the article for reasons of legibility.

2 The focus on individual choice as a way of constructing subjects and managing collective responsibilities is not unique to the realm of food. See Rose (1992).

3 Also, Lizardo's (2004) work suggests that Bourdieu's development of the 'habitus' concept can be seen as a form of cognitive sociology, as it demonstrates the 'cognitive structures that agents bring to bear in their practical knowledge of the social worlds thus structured' (2004: 375).

4 Visual and verbal images of the 'typical' neighbourhood diet were often invoked automatically and impressionistically by respondents, suggesting that automatic consciousness (Giddens, 1984) plays a role in the conceptualization of prototypical neighbourhood diets.

5 Following the first interview, participants were asked to take food photos (e.g. favourite/disliked foods, local restaurants) to be discussed in the second interview.

6 Given the small sample size and the qualitative nature of our data, it was not possible to control for income or social class in our neighbourhood comparison. Instead, our intention was to use interpretive analysis to explore how class, income and neighbourhood work together to create prototypical eating styles. For an elaboration of how ethical eating varied by social class in this sample (Johnston et al., 2011).

7 We are aware of the unequal maternal burden for domestic care work in western societies, including food provision and forging a family food identity (Doucet, 2006; Fox, 2009; Hochschild, 1989; James and Curtis, 2010; Mellor et al., 2010; Walzer, 1989). These unequal burdens clearly influenced the gender balance in our sample, and shape responsibility for providing ethical food products within the home. Regarding ethical eating and place, male and female participants expressed similar conceptions of their neighbourhood retail environment and the prototypical eater. While we touch on some of the ways in which food habits and ideals were gendered and racialized, our primary focus in this article is social class (but see Cairns et al., 2010; Szabo, 2011).

8 In Riverdale, three families were weakly engaged with ethical eating discourse; seven had moderate or high engagement. In Parkdale, five families were weakly engaged; five had moderate or high engagement (see Johnston et al., forthcoming). 


\section{References}

Baker D, Hamshaw K and Kolodinsky J (2009) Who shops at the market? Using consumer surveys to grow farmers' markets: Findings from a regional market in Northwestern Vermont. Journal of Extension 47(6): 1-9.

Barnett C, Cloke P, Clarke N and Malpass A (2010) Globalizing Responsibility: The Political Rationalities of Ethical Consumption. RGS-IBG Book Series. London: Wiley-Blackwell.

Beagan BL, Ristovski-Slijepcevic S and Chapman GE (2010) People are just becoming more conscious of how everything's connected: 'Ethical' food consumption in two regions of Canada. Sociology 44(4): 751-69.

Bennett T, Savage M, Silva E, Warde A, Gayo-Cal M and Wright D (2009) Culture, Class, Distinction. New York: Routledge.

Boudon R (1998) Social mechanisms without black boxes. In: Hedstrom P and Swedberg R (eds) Social Mechanisms: An Analytical Approach to Social Theory. Cambridge: Cambridge University Press.

Bourdieu P (1977) Outline of a Theory of Practice. New York: Cambridge University Press.

Bourdieu P (1984) Distinction: A Social Critique of the Judgment of Taste. Nice R (trans1.). Cambridge, MA: Harvard University Press.

Bourdieu P (1999) The Weight of the World. Cambridge: Polity Press.

Bourdieu P (2005) The Social Structures of the Economy. Cambridge: Polity Press.

Brown E, Dury S and Holdsworth M (2009) Motivations of consumers that use local, organic fruit and vegetable box schemes in Central England and Southern France. Appetite 53(2): 183-18.

Bruun HH (2001) Weber on Rickert: From value relation to ideal type. Max Weber Studies 1(2): $138-60$.

Bugge AB (2011) Lovin' it? A study of youth and the culture of fast food. Food, Culture \& Society 14(1): 71-89.

Butler T with Robson G (2003) London Calling: The Middle Classes and the Remaking of Inner London. Oxford: Berg.

Cairns K, Johnston J and Baumann S (2010) Caring about food: Doing gender in the foodie kitchen. Gender and Society 24(5): 591-615.

Caplan P (1997) Approaches to the study of food, health and identity. In: Caplan P (ed.) Food, Health and Identity. New York: Routledge, 1-31.

Cerulo K (2010) Mining the intersections of cognitive sociology and neuroscience. Poetics 38: 115-32.

Chaiken S and Trope Y (1999) Dual-Process Theories in Social Psychology. New York: Guilford Press.

City of Toronto (2006) South Parkdale neighbourhood profile: North Riverdale neighbourhood profile. Available at: http://www.toronto.ca/demographics/profiles_map_and_index.htm (accessed 16 May 2011).

DeSoucey M (2010) Gastronationalism: Food traditions and authenticity politics in the European Union. American Sociological Review 75(3): 432-55.

Doucet A (2006) Do Men Mother? Fathering, Care and Domestic Responsibility. Toronto: University of Toronto Press.

Douglas M (1966) Purity and Danger: An Analysis of Concepts of Pollution and Purity. London: Routledge and Kegan Paul.

Eliaeson S (2000) Max Weber's methodology: An ideal type. Journal of the History of the Behavioural Sciences 36(3): 241-63.

Ellaway A and Macintyre S (2000) Shopping for food in socially contrasting localities. British Food Journal 102(1): 52-9. 
Fleck L (1979) Genesis and Development of a Scientific Fact. Chicago University of Chicago Press.

Fox B (2009) When Couples Become Parents: The Creation of Gender in the Transition to Parenthood. Toronto: University of Toronto Press.

Giddens A (1984) The Constitution of Society. Outline of a Theory of Structuration. Berkeley, CA: University of California Press.

Gidley B and Rooke A (2010) Asdatown: The intersections of classed places and identities. In: Taylor Y (ed.) Classed Intersections: Spaces, Selves, Knowledges. Farnham: Ashgate.

Gilbert D (2008) The American Class Structure in an Age of Growing Inequality. London: Sage.

Goldthorpe JH (with Llewellyn C and Pane C) (1987) Social Mobility and Class Structure in Modern England. New York: Oxford University Press.

Govindasamy R, Zurbriggen M, Italia J, Adelaja A, Nitzsche P and VanVranken R (1998) Farmers Markets: Consumer Trends, Preferences, and Characteristics. New Jersey Agricultural Experiment Station. P-02137-77-98. Newark: Department of Agricultural, Food, and Resource Economics, Rutgers, The State University of New Jersey.

Guthman J (2008) Neoliberalism and the making of food politics in California. Geoforum 39: $1171-83$.

Hochschild A (1989) The Second Shift: Working Parents and the Revolution at Home. New York: Viking Penguin.

James A and Curtis P (2010) Family displays and personal lives. Sociology 44(6): 1163-80.

Johnston J (2008) The citizen-consumer hybrid: Ideological tensions and the case of Whole Foods Market. Theory and Society 37: 229-70.

Johnston J and Baumann S (2010) Foodies: Democracy and Distinction in the Gourmet Foodscape. New York: Routledge.

Johnston J and Szabo M (2011) Reflexivity and the Whole Food Market shopper: Shopping for change, or cruising for pleasure? Agriculture and Human Values 28(3): 303-19.

Johnston J, Szabo M and Rodney A (2011) Good food, good people: Understanding the cultural repertoire of ethical eating. Journal of Consumer Culture 11(3): 293-318.

Lamont M (1992) Money, Morals, and Manners: The Culture of the French and the American Upper-Middle Class. Chicago University of Chicago Press.

Lareau A (2002) Invisible inequality: Social class and childrearing in black families and white families. American Sociological Review 67: 747-76.

Lawler S (2000) Mothering the Self: Mothers, Daughters, Subjects. London: Routledge.

Lizardo O (2004) The cognitive origins of Bourdieu's Habitus. Journal for the Theory of Social Behavior 34(4): 375-401.

Lockie S (2009) Responsibility and agency within alternative food networks: Assembling the 'citizen consumer'. Agriculture and Human Values 26(3): 193-201.

Lury C (1997) Consumer Culture. Cambridge: Polity Press.

Mellor J, Blake M and Crane L (2010) When I'm doing a dinner party I don't go for the Tesco cheeses, it's that sort of level, you know?' Class distinctions, friendship and home entertaining. Food, Culture \& Society 13: 115-34.

Moore LV and Roux AVD (2006) Associations of neighbourhood characteristics with the location and type of food stores. American Journal of Public Health 96(2): 325-31.

Morland K, Wing S, Roux AD and Poole C (2002) Neighbourhood characteristics associated with the location of food stores and food service places. American Journal of Preventive Medicine 22(1): 23-9.

Oluwabamide AJ and Akpan NS (2010) Environmental and cultural patterns in nutrition: A comparison of food patterns in two Nigerian societies. Anthropologist 12(2): 95-8.

Pollan M (2006) The Omnivore's Dilemma: A Natural History of Four Meals. New York: Penguin. 
Popkin BM, Duffey K and Gordon-Larsen P (2005) Environmental influences on food choice, physical activity and energy balance. Physiology and Behaviour 86(5): 603-13.

Rosch E and Lloyd B (1978) Cognition and Categorization. Philadelphia, PA: Lawrence Erlbaum.

Rose N (1992) Governing the enterprising self. In: Heelas P and Morris P (eds) The Values of Enterprise Culture: The Moral Debate. New York: Routledge.

Savage M (2010) The politics of elective belonging. Housing, Theory and Society 27(2): 115-35.

Schultz PW (2002) Knowledge, education and household recycling: Examining the knowledge-deficit model of behaviour change. In: Dietz T and Stern P (eds) Education, Information and Voluntary Measures in Environmental Protection. Washington, DC: National Academy of Sciences, 67-82.

Seyfang G and Paavola J (2008) Inequality and sustainable consumption: Bridging the gaps. Local Environment 13(8): 669-84.

Skeggs B (2004) Class, Self, Culture. New York: Routledge.

Slater T (2005) Toronto's South Parkdale Neighbourhood. Toronto: Centre for Urban and Community Studies, University of Toronto.

Smith C and Morton LW (2009) Rural food deserts: Low-income perspectives on food access in Minnesota and Iowa. Journal of Nutrition Education and Behaviour 41(3): 176-87.

Squires L, Juric B and Cornwell TB (2001) Level of market development and intensity of organic food consumption: Cross-cultural study of Danish and New Zealand consumers. Journal of Consumer Marketing 18(5): 392-409.

Starr MA (2009) The social economics of ethical consumption: Theoretical considerations and empirical evidence. Journal of Socio-Economics 38(6): 916-25.

Statistics Canada (2006) Census tract profiles for 0004.00, 0005.00, 0007.01, 0007.02, Toronto (CMA), Ontario.

Statistics Canada (2010) Census tract profile for 0071.00, Toronto (CMA) and Ontario.

Storey M, Neumark-Sztainer D and French S (2002) Environmental influences on adolescent eating behaviours. Journal of the Dietetic Association 102: S40-S51.

Szabo M (2011) The challenges of 're-engaging with food': Connecting employment, household patterns and gender relations to convenience food consumption in North America. Food, Culture \& Society 14(4): 547-66.

Taylor Y (2010) Privileged locations? Sexuality, class and geography. In: Taylor Y (ed.) Classed Intersections: Spaces, Selves, Knowledges. Farnham: Ashgate.

Vaisey S (2008) Socrates, Skinner, and Aristotle: Three ways of thinking about culture in action. Sociological Forum 23(3): 603-13.

Vaisey S (2009) Motivation and justification: A dual-process model of culture in action. American Journal of Sociology 114(6): 1675-715.

Walzer S (1989) Thinking about the Baby: Gender and Transitions into Parenthood. Philadelphia, PA: Temple University Press.

Wacquant L (1991) Making class: The middle-class(es) in social theory and social structure. In: McNall SG, Levin RF and Fantasia R (eds) Bringing Class Back in Contemporary Historical Perspectives. Boulder, CO: Westview Press.

Warde A (1999) Convenience food: Space and timing. British Food Journal 101(7): 518-27.

Weatherell C, Tregear A and Allinson J (2003) In search of the concerned consumer: UK public perceptions of food, farming and buying local. Journal of Rural Studies 19(2): 233-44.

Webber R (2007) The metropolitan habitus: Its manifestations, locations, and consumption profiles. Environment and Planning 39: 182-207.

Weber M (1949) Objectivity in social science. In: Shils EA and Finch HA (eds) The Methodology of the Social Sciences. York: Simon \& Schuster, The Free Press.

Zukin S (2010) Naked City: The Death and Life of Authentic Urban Places. Oxford: Oxford University Press. 
Josée Johnston is Associate Professor of Sociology at the University of Toronto. She focuses her research on the sociological study of food, investigating aspects of culture, consumerism, politics, and the environment. Johnston co-authored (with Shyon Baumann) Foodies: Democracy and Distinction in the Gourmet Foodscape (Routledge, 2010). She has published articles in publications including American Journal of Sociology, Theory and Society, Signs: Journal of Women in Culture and Society, Gender and Society, and Antipode: A Radical Journal of Geography. Current research projects are focused on the following: 1) Ethical consumption (funded by the Social Sciences and Humanities Research Council of Canada); 2) Family food practices (funded by the Canadian Institute for Health Research); and 3) Consumer motivations in alternative agricultural initiatives (funded by an Ontario Government Early Researcher Award).

Alexandra Rodney is a second year $\mathrm{PhD}$ student at the University of Toronto, and a recipient of the Ontario Graduate Scholarship. As part of her doctoral research, she is writing an analysis of how infertility patients are portrayed in the media. Her research interests include health, culture, and gender as well as use of the internet for health support.

Michelle Szabo is a PhD candidate in the Faculty of Environmental Studies at York University, Toronto. Her interests include the sociology of food and cooking; ethical consumption; gender and foodwork; and household food habits as they relate to health, sustainability and equity in the food system. Her dissertation examines the motivations for and meanings of domestic cooking among involved male domestic cooks. She has published articles in Food, Culture \& Society, Agriculture \& Human Values and the Journal of Consumer Culture.

Date submitted February 2011

Date accepted December 2011 